\title{
Are people incidentally exposed to news on social media? A comparative analysis
}

\author{
Richard Fletcher (corresponding author) \\ Reuters Institute for the Study of Journalism \\ Department of Politics and International Relations \\ University of Oxford \\ OX2 6PS \\ UK \\ +44 (0)1865 611075 \\ richard.fletcher@politics.ox.ac.uk \\ Rasmus Kleis Nielsen \\ Reuters Institute for the Study of Journalism \\ Department of Politics and International Relations \\ University of Oxford \\ OX2 6PS \\ UK \\ +44 (0)1865 611074 \\ rasmus.nielsen@politics.ox.ac.uk
}

Acknowledgements: The authors would like to thank all those who worked on the 2015 Reuters Institute Digital News Report project for their input.

Richard Fletcher is a research fellow at the Reuters Institute for the Study of Journalism. He is lead researcher and co-author of the annual Reuters Institute Digital News Report (2017, with Nic Newman, Antonis Kalogeropoulos, David AL Levy, and Rasmus Kleis Nielsen). He is primarily interested in global trends in digital news consumption, comparative media research, the use of social media by journalists and news organizations, and more broadly, the relationship between computer-based technologies and journalism.

Rasmus Kleis Nielsen is director of research at the Reuters Institute for the Study of Journalism and editor-in-chief of the International Journal of Press/Politics. His work focuses on changes in the news media and on political communication, and the role of digital technologies in both. Recent books include The Changing Business of Journalism and its Implications for Democracy (2010, edited with David Levy), Ground Wars: Personalized Communication in Political Campaigns (2012), and Political Journalism in Transition: Western Europe in a Comparative Perspective (2014, edited with Raymond Kuhn). 


\begin{abstract}
Scholars have questioned the potential for incidental exposure in high-choice media environments. We use online survey data to examine incidental exposure to news on social media (Facebook, YouTube, Twitter) in four countries (Italy, Australia, UK, USA). Leaving aside those that say they intentionally use social media for news, we compare the number of online news sources used by social media users who do not see it as a new platform, but may come across news while using it (the incidentally exposed), with people who do not use social media at all (non-users). We find that (i) the incidentally exposed use significantly more online news sources than non-users, (ii) the effect of incidental exposure is stronger for younger people and those with low interest in news, and (iii) stronger for users of YouTube and Twitter than for users of Facebook.
\end{abstract}

\title{
Keywords
}

social media, incidental exposure, news, comparative research, journalism, Facebook, YouTube, Twitter.

In twentieth century mass media environments, television provided a powerful platform for incidental exposure to news. People were motivated to watch television for reasons that had little to do with news, but in the process they ended up exposed to news content (Neuman et al., 1992). Many have argued that the move to an increasingly digital and increasingly highchoice media environment in the twenty-first century means that incidental exposure will wane, and selective exposure - where only those actively interested in seeking out news are exposed to it - will grow (Bennett and Iyengar, 2008). More specifically, it is argued that in high-choice environments those most interested get more news and engage more, but those least interested get less news and engage less (Prior, 2005). However, others believe that 
increasing supply and ease of access will lead to more diverse news use and more engagement than the mass media environment that preceded it (Benkler, 2006; Chadwick, 2013).

Since many of these arguments were put forward, there has been huge worldwide growth in the use of social media. By 2015 , around $87 \%$ of the online population of the USA said that they used at least one social network in the previous week (Newman et al., 2015). Facebook, the world's most popular social network, has over one billion daily users (Zuckerberg, 2015). In most Western countries, and in many other parts of the world, YouTube and Twitter are also among the most popular networks, claiming around one billion and 330 million active users respectively. Though all three networks initially focussed on user-generated content, they now increasingly act as 'intermediaries' between established publishers and consumers (Nielsen and Ganter, 2017). None of the networks considered here started out with the intention to provide news, but as their popularity grew, and their functionality expanded, all came to be used as a source of news by a significant proportion of their users, with considerable variation across networks (Pew, 2016), and across countries (Newman et al., 2015). Yet despite sharp increases in news use, with some exceptions (Valeriani and Vaccari, 2016; Boczkowski et al., 2017; Gil de Zúñiga et al., 2017) there has been little recent research on the extent of incidental exposure to news on social media.

In this article, we analyse whether the growing role of social media platforms like Facebook, Twitter, and YouTube is increasing incidental exposure in a media environment otherwise increasingly characterized by selective exposure. We use data from the <ANONYMOUS> survey (Newman et al., 2015; Fletcher et al., 2015) to compare differences in the number of sources of news used online between three non-overlapping categories of social media user: 'non-users', those who have the potential to be 'incidentally exposed', and 'news users'. Non-users are people who do not use social media at all for any 
purpose. News users are people who deliberately and intentionally use social media to get the news. This leaves a third, middle category; those who have the potential to be 'incidentally exposed'. These are people that mainly use social media for other purposes, but who in the process of doing so might be exposed to news content. Leaving aside people who intentionally use social media for news (news users), our aim here is to compare non-users with the incidentally exposed. We also test whether the effect of incidental exposure on social media is stronger amongst groups associated with low news use, in particular young people and those with low interest in the news. We analyse data from four countries with substantially different media systems and patterns of online news consumption (Australia, Italy, UK, USA), and compare across three social media platforms with different functionalities and designs (Facebook, YouTube, Twitter).

\section{Literature Review}

Empirical research has demonstrated a link between news consumption and political participation (see e.g. Norris, 2000). However, there are 'costs' to the individual - in terms of time, effort, and motivation - if they wish to acquire this information (Downs, 1957). In the digital age, some of these costs have been dramatically reduced, but have not been entirely reduced to zero. Because much news consumption is intentional, people most interested in the news tend to consume more of it (Graber, 1984). Consequently, democratic societies rely on incidental exposure to political information, and news coverage more generally, in order to engage groups that are not motivated to actively seek it out.

Incidental exposure to news is a concept familiar to communication scholars. Most printed publications aiming for a mass audience package news alongside non-news content, and studies from as early as the 1940s noted that some people read newspapers for reasons that had little to do with news (e.g. Berelson, 1949). Later, television news bulletins formed 
part of linear schedules that meant people often found themselves watching news if they had tuned in early to entertainment programmes, or carried on watching afterwards (Neuman et al., 1992). Some public service broadcasters deliberately scheduled news programmes at peak viewing times, creating media environments where incidental exposure was more likely, thus offering better “information opportunities” for citizens (Esser et al., 2012) and potentially reducing knowledge gaps (Aalberg and Curran, 2012).

In the latter part of the twentieth century, many countries transitioned from low choice to high choice media environments, first with the introduction of cable television, and later with the growth of the web. This prompted debates over whether greater choice and availability meant that people would self-select away from news. Perhaps most notably, Prior (2005) argued that content preferences become more important in high choice environments. Based on data on television viewers in the USA, he showed that those with stronger preferences for entertainment self-selected away from news, with the effect of lowering political knowledge and turnout, with only those most interested in politics benefitting from the wealth of available information. Others have argued that the way people use the web means that although it is undoubtedly a high choice environment where attention is often directed towards particular tasks, the potential for incidental exposure to news still exists. In an earlier study, Tewksbury et al. (2001) found a link between Internet use and political knowledge, attributing this to incidental exposure to news on web portals (such as Yahoo! and Lycos) favoured by early users. Kim et al. (2013) found a positive association between incidental news exposure online and political participation in the USA, but also observed that those with a stronger preference for entertainment benefitted less.

During the last decade, the rapid rise of social media has attracted significant attention from scholars. Some studies have found an association between social media use and various desirable outcomes, such as civic or political participation (see e.g. Gil de Zúñiga et al., 
2012), but did not explicitly link this to incidental exposure. More recently, the increased use of social media has sparked fears that a process of self-selection reinforced by ever more responsive and sophisticated algorithmic selection will create echo chambers, or worse, trap people inside "filter bubbles", where they will only ever be shown more of the things they already like, with the things they do not like hidden from them (Pariser, 2011). This idea has prompted important empirical research on the impact of social media on the extent to which people are exposed to political ideas that differ from their own, and in some cases, the impact this might have on political knowledge and participation (Bakshy et al., 2015; Barberá et al., 2015; Flaxman et al., 2016; Heatherly et al., 2016; Messing and Westwood, 2014).

Most of this research, however, does not confirm people’s worst fears. Messing and Westwood (2014) found that social media often provides users with information from politically heterogeneous sources, and that social endorsements play a more important role in determining what users choose to consume, reducing the effect of partisan selective exposure. Flaxman et al. (2016) examined the web histories of 50,000 internet users and found that while social media users tend to be more polarized, they are nonetheless exposed to more content from the other side of the political spectrum. The largest relevant study to make use of Facebook data did, however, find some evidence that selective exposure shapes what people see (Bakshy et al., 2015). Compared with what they would see if they were friends with a random selection of Facebook users, people in fact see slightly see less news from sources with different political views, primarily due to political homophily, but also to a lesser extent due to Facebook’s algorithms. Users were also less likely to click through to read stories expressing an opposing view. This suggests that selective avoidance, friend selection (homophily), and algorithmic ranking all might have a small limiting effect.

Importantly, in many of these studies, exposure to information on social media is compared with what we might think of as an idealised form of diversity, because it is not 
usually possible to use the data to make comparisons with what people who do not use social media experience. Even if we can use data from social media to show that algorithms to some extent encourage patterns of communication rooted in ideological or political preferences, it remains unclear whether using those same systems offers more benefits than not using them at all. After all, social media may simultaneously enable people to access more information of all types, particularly those they disagree with or have little interest in. This is of critical importance if we want to understand the role of social media in the news ecosystem.

Focussing on incidental exposure to news is one way of approaching this broader issue. The potential for incidental exposure to news on social media clearly exists, simply because people use it for a variety of reasons, and are not in complete control of what they see. Data from 2012 showed that only 18\% of social media users in the USA unfollowed or unfriended others because of political content they had posted (Pew, 2012a). This suggests that most users execute only "partial control” over their news feeds, with older, male, partisans more likely to do so, thus creating widespread potential for incidental exposure to political information, particularly amongst the least engaged groups (Bode, 2016b). Despite this, however, other studies concluded that social media use does not lead to significant increases in political learning (Bode, 2016a; Bowyer et al., 2015).

People might be incidentally exposed to news on social media in several ways. Users might see others discussing news stories, or posts containing first-hand information related to news. They might be shown links to news content provided by external sources, such as established print, broadcast and digital-born publishers. On many social networks these links are displayed as previews (including headlines, text snippets, and multimedia), meaning that people are arguably exposed to news content even if they do not click on the link. Those that do click through, however, are exposed to full stories in a way that is no different to what they would see if they had arrived via the website's homepage. 
However, we should also take seriously the idea that this potential may not be realised, either because people’s networks are dominated by likeminded users, because they have customised their settings to minimize the amount of news they see, or because algorithms have become so responsive that they no longer surface anything that does not align with past behaviour. In the most relevant study in this area, Valeriani and Vaccari (2016) used survey data from three countries (Germany, Italy, UK) to show that increased self-reported levels of incidental exposure to political information on social media are positively associated with political participation. This relationship is moderated by interest in politics, with those least interested benefitting more. We aim to complement this study by making an explicit comparison between non-users and the incidentally exposed, as well as moving beyond it by examining the effect of incidental exposure to news on different social networks.

\section{Hypotheses and Research Questions}

On this basis, we formulate a series of hypotheses and research questions. First, because previous studies have found associations between social media use and political or civic participation, and because news consumption is often seen as an important enabling step (though it is debatable whether news consumption alone constitutes a form of participation), we hypothesise that people who say they typically use social networks for reasons other than news will nonetheless use more sources of news than non-users.

$H_{1}$ : Those incidentally exposed to news on social media will use more different sources of online news than non-users. 
If present, the effect of incidental exposure will likely vary depending on individual characteristics. Heavy news users will likely benefit less from incidental exposure because they are more likely to be already consuming news from lots of different outlets. However, groups that typically consume news less, such as younger people and those with low levels of interest, may benefit more; particularly as we already have some evidence suggesting that curating social feeds is negatively associated with age and interest in politics (Bode, 2016b). Therefore, we hypothesise that the effect of incidental exposure on social media on the number of different online news sources used will be negatively moderated by both age and interest in news.

$\mathrm{H}_{2}$ : The effect of incidental exposure to news on social media on the number of different online news sources used will be negatively moderated by interest in news.

$H_{3}$ : The effect of incidental exposure to news on social media on the number of different online news sources used will be negatively moderated by age.

Though media scholars are used to seeing national variation in news consumption patterns because of differences in media systems, it is also true that social media platforms operate in a broadly consistent way across countries. This introduces the possibility that incidental exposure to news on these platforms occurs in a similar way, and to a similar extent, in different national contexts. But, this is an open question.

$R Q_{1}$ : Does the relationship between incidental exposure to news on social media and number of different online news sources used vary from country-to-country? 
We lack a comprehensive account of how Facebook, Twitter, and YouTube are used. However, it is likely they are used quite differently, simply because different people use them, and they offer different functionalities. Kim and Lee (2016) found that people who are primarily motivated by forming relationships tend to prefer symmetrical social networks like Facebook, where users are linked based on mutual consent. Those primarily motivated by information acquisition, including news, tend to prefer asymmetrical networks like Twitter and YouTube, where one-way links between users are permitted. Perhaps as a result, each social network has a different relationship with news. Twitter is popular with public figures, journalists and news organizations, and many see it as a news source in its own right (Broersma and Graham, 2012). Many news organizations upload their video content to YouTube, but some of the most popular news videos on YouTube consist of eyewitness footage uploaded by citizen journalists (Pew, 2012b). In the past, Facebook primarily acted as a gateway to news websites because users shared links with their friends, but more recently, Facebook has used its enormous user base to encourage news publishers to upload their content directly to the platform. However, given these insights relate to intentional news use, it is not clear what they imply for incidental exposure.

We also lack details of the inner-workings of each of these networks, particularly when it comes to algorithmic selection. However, it is clear that they all rely on it to some degree. Facebook’s news feed algorithm (previously called EdgeRank) has been at the heart of the platform for over ten years, and determines much of what users see. In January 2015 (two weeks before the survey on which this study is based was carried out) Twitter launched their "While you were away" feature, designed to automatically surface prominent tweets users may have missed since they last logged on (Rosania, 2015). YouTube relies on search algorithms to supply users with relevant results, in addition to automatically recommending similar videos based on past behaviour. It therefore seems likely that the impact of incidental 
exposure on news use will also vary. Again, however, we lack the information required to form a specific hypothesis about the levels of incidental exposure on each network, and leave this as an open question.

$R Q_{2}$ : Does the effect of incidental exposure to news on the use of different online news sources vary according to the social network used?

\section{Data}

The data we use address our hypotheses and research questions comes from the 2015 <ANONYMOUS > survey (Newman et al., 2015; Fletcher et al., 2015). The survey was conducted by $<$ ANONYMOUS $>$ in partnership with the <ANONYMOUS $>$ during early February 2015. An online questionnaire was used to survey over 30,000 respondents across a total of 18 countries. Samples were drawn from panels within each, with respondents invited to complete the survey on the basis of quotas for age, gender, and region. Samples were weighted according to census data to match the national population. Respondents who said that they used news less than once a month were filtered out.

The data has several key strengths. First, the survey contained an extensive list of questions that capture news media use across platforms, as well as attitudes towards news (interest in news, trust in news, etc.). In contrast to many international surveys, news use is measured at the brand level, ultimately allowing us to count the number of news sources used by each respondent, and to separate out the use of different social networks. Key demographic data was also collected, allowing us to control for a range of factors. Additionally, the survey captured data using the same questions at the same point in time across a range of different countries, thus affording a comparative analysis. 
The data also has limitations that need to be kept in mind. First, the survey questions required to examine incidental exposure to news on different social networks (described in the next section) were only asked in four of the 18 countries surveyed (Italy, Australia, UK, USA). This dictated the country selection and the scope of comparative part of the analysis. Fortunately, these countries exhibit quite different patterns of online news consumption. In Australia over half (51\%) of the online population use social media for news, compared to 46\% in Italy, $40 \%$ in the USA, and just 36\% in the UK. More broadly, these countries have different media systems. The UK media environment has seen relatively high levels of state intervention reflected in the widespread use of the BBC, with lower levels of intervention in Italy and Australia, and lower still in the USA. Historically, per capita newspaper readership was comparatively high in the UK and the USA, slightly lower in Australia, and lower still in Italy.

It is important to keep in mind that the data is drawn from an online panel, and as a result, the respondents do not represent a random sample. Also, as the data is cross-sectional, it is not ideally suited to identifying cause and effect (which we will partly address during the analysis stage). Finally, as with all surveys of media use, reliance on recall means that the data may not always provide a completely accurate picture of people’s actual news media use (Prior, 2009). But despite all of these important limitations, a survey is the only realistic option for addressing our hypotheses and research questions. Most passive tracking systems (e.g. comScore) are not able to record how people use social media, and data collected by social media platforms is very rarely made available to outside researchers.

\section{Measures}

Our dependent variable is the number of online news sources each respondent said they used in the last week. In contrast to other studies, we did not aim to measure civic or political 
participation, but rather the mechanisms that form a link between it and social media use (though news consumption alone may constitute a form of participation for some). Rather than asking people to provide a figure, the measure was produced by asking respondents to select from a list of around 30 of the most popular online news sources in each country. For example, in the UK the question read: "Which, if any, of the following have you used to access news in the last week via online platforms (web, mobile, tablet, e-reader)? Please select all that apply.”, with the available options listed as brand names such as 'BBC News online' and 'Guardian online'. Respondents were also able to list up to three other online news sources not included on the list, which also contributed to the total. The question reminds people that they should include any news sources accessed while using a mobile device. The question did not specifically ask respondents to select a news brand if they had just seen a preview on social media, or if they had seen a news story discussed by others, but does imply they should do so if they clicked through and used a branded news destination to read or watch the full story. Seeing a news preview on social media arguably counts as exposure, but it is unlikely that our question will have captured this. Therefore, our measure potentially underestimates this dimension of incidental exposure.

Our primary independent variable is type of social media use. This variable has three non-overlapping categories: non-users, the incidentally exposed, and news users. To divide people into these groups we asked all respondents which social networks (if any) they used for any purpose in the last week from a list of around 15 of the most popular within each country. Those who did not select any social networks from this list were placed into the 'non-users' category (12\% of the sample from all four countries). The next step was to identify the 'news users'. To do this, respondents were first asked which social networks they had used to find, read, watch, share or discuss the news in the last week. Then, to more accurately filter respondents, those that selected either Facebook, Twitter, or YouTube were 
shown a separate follow up question that asked: "You say you use < social network> for news. Which of the following statements applies best to you?” with respondents able to choose either (i) I think of < social network> as a useful way of getting news, (ii) I mostly see news when I'm on <social network> for other reasons, or (iii) Don't know. If a respondent said that they used more than one of the three networks, they were asked the same question separately for each. Those that selected the option (i) for any of the three networks were placed into the 'news users' category (23.4\%). Those that selected options (ii) or (iii) were placed in the 'incidentally exposed' category (58.2\%), along with those who said they used social media, but not for news. ${ }^{1}$ In other words, the incidentally exposed are those that use each social network for any purpose (but say they do not get news there), and those who say they come across news on social platforms while they use them for other purposes. In general, this can be thought of as a conservative grouping strategy, as it would likely mean that people who did not actually see any news on each network were placed into the incidental exposure category, artificially lowering the average number of online news sources used by this group, but allowing more confidence in any remaining differences between nonusers and the incidentally exposed. ${ }^{2}$

We only asked the follow-up question for Facebook, Twitter and YouTube because asking it for all networks would have dramatically increased the survey length for some respondents, and because we suspected that only a small minority of social media users would use other networks but not one these three. This turned out to be correct, as the recoding process left just $6.3 \%$ unclassified, meaning that almost $95 \%$ of respondents were correctly categorised using just three follow-up questions. The $6.3 \%$ were removed from the analysis.

We also make use of control variables based on age $(M=48.42, S D=15.91)$, gender (48.2\% male), highest level of education $(M=3.85, S D=1.32$, measured on a 1-6 scale), 
trust in news $(M=3.05, S D=.99,1-5$ scale $)$, interest in news $(M=2.95, S D=.85,0-4$ scale $)$, frequency of internet use ( $M=6.68, S D=1.19,1-8$ scale), and other potential sources of incidental exposure, such as using news aggregators (6.2\%) and using search engines to search for news topics (26.1\%).

\section{Results}

Before addressing our hypotheses and research questions, we present some descriptive statistics to help with interpretation. Across all countries, non-users said they used an average (mean) of $1.43(S D=1.77)$ online news sources in the previous week, compared to 2.30 (SD $=2.27$ ) for the incidentally exposed. Those who intentionally used social media for news used an average of $3.38(S D=3.11)$. Figures by country are provided in Table 1. Here, we can see that in every country the incidentally exposed use more different sources of news than non-users.

\section{$<$ TABLE 1 HERE $>$}

To partly address some of the limitations around causation and the use of crosssectional data, we use propensity score matching to treat the data before analysing it further. The purpose of matching is to modify a dataset so that it closely resembles that produced by a randomized experiment (for an overview see Stuart, 2010). Propensity score matching ensures that differences found between categories of respondent are unrelated to other variables included in analysis by trimming the dataset so that each respondent within a category based on the independent variable is matched with one respondent in the other group that has similar observed characteristics. This process was performed using the 'MatchIt' package for the statistical language R, using the 'nearest neighbour' approach. 
Here, we are interested in the differences between non-users (the control group) and the incidentally exposed (the treatment group). As matching is only appropriate for binary independent variables, respondents in the news users category were removed from the analysis because they are not required for addressing our hypotheses. Then, those variables able to predict incidental exposure to news on social media were used to create a score for each respondent that refers to their propensity to be in this category. These scores were then used to identify pairs of similar respondents that differ only in terms of whether they are incidentally exposed. This reduced the number of respondents in the dataset from 8492 to 5765, but increases our confidence in the analysis because the models are less influenced by respondents that differ from one another in terms of observed characteristics.

To address our hypotheses and research questions, we use a similar approach to Valeriani and Vaccari (2016) in their study of the impact of incidental exposure to politics on social media on political participation. As our dependent variable is a 'count' variable, we use Poisson regression models. ${ }^{3}$ Prior to the matching procedure, all non-categorical independent and control variables were adjusted to range between 0 and 1 to make coefficients comparable. We have pooled the data from all four countries, and will test for national differences by introducing country dummy variables and interaction terms.

\section{$H_{1}$ : Those incidentally exposed to news on social media will use more different sources of online news than non-users.}

This hypothesis is tested using Model 1 in Table 2. The model includes the variable for different types of social media user in the first row, with non-users as the reference category. The significant and positive regression coefficient $(b=.26, p<.001)$ reveals that those who are incidentally exposed to news on social media use more different sources of 
online news than non-users, even using the matched dataset and controlling for a number of other demographic variables, news attitudes, and other types of news access. Hypothesis 1 is therefore supported.

\section{$\mathrm{H}_{2}$ : The effect of incidental exposure to news on social media on the number of different online news sources used will be negatively moderated by interest in news.}

We test this hypothesis by adding an interaction term for incidental exposure and interest in news. This is summarised in Model 2. Here, the beta coefficient is both significant and negative $(b=-.50, p<.001)$. Given that incidental exposure is positively associated with number of online news sources used, this indicates that interest in news does indeed negatively moderate the effect of incidental exposure on the number of online news sources used. All things being equal the effect of incidental exposure is greater for those less interested in news than for those with high interest. If we hold all other variables at their means or medians, we can use Model 2 to estimate that for respondents whose interest in news is one standard deviation below the mean, being incidentally exposed to news on social media results in a 52\% increase in the number of sources used (compared to non-users), whereas those with interest levels one standard deviation above the mean the increase is $25 \%$. Hypothesis 2 is therefore supported.

$H_{3}$ : The effect of incidental exposure to news on social media will on the number of different online news sources used will be negatively moderated by age.

We test hypothesis 3 by repeating the above process, but instead adding an interaction between incidental exposure and age (see Model 3). Again, we see that the coefficient for this 
interaction is significant and negative $(b=-.42, p<.05)$, indicating the relationship is negatively moderated by age. Younger respondents (those aged one standard deviation below the mean age) receive a $47 \%$ boost in the number of online news sources they use if they are incidentally exposed on social media, compared to a $28 \%$ boost for older respondents. Hypothesis 3 is thus supported.

$R Q_{1}$ : Does the relationship between incidental exposure to news on social media and number of online news sources used vary from country-to-country?

Adding a final set of interaction terms to the model for incidental exposure and country can help us address this research question. Model 4 shows, given that the coefficients for the interactions are negative, that the effect of incidental exposure on number of online news sources used is strongest in the UK (the reference category). The effect in the UK is significantly stronger than in Australia $(b=-.22, p<.05)$ and Italy $(b=-.23, p<.05)$, but changing the reference category for the country variable and reproducing the model did not result in any significant differences between any of the other countries. As such we can say that the effect of incidental exposure on the number of online sources uses does differ country to country, but only by a small amount.

$<$ TABLE 2 HERE $>$

$R Q_{2}:$ Does the effect of incidental exposure to news on the use of different online news sources vary according to the social network used? 
To answer this research question we created three new independent variables (i) incidental exposure to news on Facebook, (ii) incidental exposure to news on YouTube, and (iii) incidental exposure to news on Twitter. These were created using the same procedure outlined in the 'Measures' section, but each time, respondents were only categorised based on their use of the relevant network. We were unable to use the same matched dataset, simply because the independent variable will be different each time, and datasets must be matched on the basis of variables that predict membership of the treatment group. We therefore produced three new matched datasets (one for incidental exposure on Facebook, one for YouTube, and one for Twitter), and a separate set of models for each (summarised in Appendix A). This allowed us to test for the effect of incidental exposure on each network, whilst controlling for use of the other two.

We can see from Model 1 in Table 3 (Appendix A) that the effect of incidental exposure on Facebook on the number of different online news sources used is both significant and positive $(b=.10, p<.001)$. However, the effect is small, and loses significance (but remains positive) when we introduce controls for YouTube and Twitter use (see Model 2 in Table 3). When we repeat the process for incidental exposure on YouTube ( $b$ $=.23, p<.001)$ and Twitter $(b=.27, p<.001)$ the coefficients remain significant and positive, even after controls for other social networks are introduced. Therefore, in response to Research Question 2, our analysis suggests that the effect is stronger on YouTube and Twitter than on Facebook. We also tested for country differences on specific networks, but were only able to detect a significantly weaker effect of incidental exposure on YouTube in Italy $(b=-.13, p<.05)$ when compared to the UK.

\section{Discussion}


We have attempted to test for incidental exposure to news on social media, and following on from this, the effect it might have on news use. Our analysis, based on quite conservative measures of what counts as news exposure, suggests that incidental exposure does indeed occur on social media, and that the incidentally exposed use more sources of news than nonusers. Given that the average number of news sources used in each country is low particularly in the UK (see Table 1) - it is likely that any increase in number of sources necessarily means an increase in diversity. For those that consume news from just one source, even the addition of just one more very similar source constitutes an increase in diversity of views providing the content is not identical. (However, for those that consume news from an above-average number of sources, incidental exposure via social media may indeed result in an echo-chamber effect if any additional sources are highly similar to what is already being used.)

We have also seen that for younger people and those less interested in news the effect of incidental exposure is stronger. Given that these groups typically consume less news, the likely reason for the stronger association is that they have more to gain from incidental exposure than those already consuming news from a wider array of sources. Or, it may be that these groups are more active and enthusiastic social media users who are part of larger networks, and as a result, are more likely to be incidentally exposed to more of everything (including news) when they are online (Lee and Kim, 2017). Either way, this means that incidental exposure to news via social media could potentially reduce knowledge gaps that result from self-selection away from news (Prior, 2005), particularly in societies with low information opportunities (Esser et al., 2012), but also in environments formerly characterised by incidental exposure when media choice was relatively low. This, in turn, could have a positive impact on outcomes like political participation and civic engagement, given previous findings (e.g. Gil de Zúñiga et al., 2017; Valeriani and Vaccari, 2016). 
The effect of incidental exposure on Twitter and YouTube appears to be stronger than on Facebook. Given that previous research has found that those primarily motivated by information seeking tend to prefer Twitter and YouTube (Kim and Lee, 2016), this could suggest a link between a stronger preference for intentional news use among the user base as a whole, and increased opportunities for incidental exposure to news for users motivated in other ways, simply because they are surrounded by a higher concentration of news content. More specifically, users of Twitter may follow others for non-news reasons, but still be exposed to news if they decide post a link to a news story. On YouTube the likely mechanism is less clear, and requires further investigation. One possibility is that people are exposed to news on the homepage, if they browse lists of the most popular videos, or are automatically recommended a news video after watching a non-news video on a similar topic.

Finally, we see only small differences in the effect of incidental exposure to news on social media from country to country. This is in one sense surprising, given that scholars are used to seeing pronounced national differences, in part due to people inhabiting media systems that tend towards a particular ideal type. However, given that the affordances of all three platforms do not vary much from country to country, it is perhaps unsurprising that we see only small differences after controlling for other factors.

We therefore conclude that environments characterised by selective exposure are accompanied by more incidental exposure via social media. These findings are substantially very important. Contrary to the concern that the move to a high-choice environment will lead to increased polarization between news lovers who seek out news and those less interested who do not (Bennett and Iyengar, 2008; Prior, 2005), and fear that social media limit the diversity of news people are exposed to (Pariser, 2011), we find that social media use is in fact significantly related with increased news use, even amongst those who come across news on social media while doing other things. 
Our results point to at least four possible areas of further research. The first concerns the potential benefits of social media use for democratic societies, and the search for an empirical basis for a more direct link between the two. Second, they open up the possibility that the non-news motivations for the use of social media, and the broader patterns of communication they produce, are important to our understanding of online news consumption specifically. Third, there is the intriguing question of whether the increased global use of a handful of social media platforms for news - that largely operate in a uniform way across borders - will have a universalizing effect on the national differences in online news consumption. Finally, because both the technical properties and user base of these platforms change over time (witness the growth of Facebook and the introduction of products like Instant Articles), it is important to continuously examine their impact on exposure to news.

\section{References}

Aalberg T and Curran J (eds) (2012) How Media Inform Democracy: A Comparative Approach. New York: Routledge.

Bakshy E, Messing S and Adamic LA (2015) Exposure to ideologically diverse news and opinion on Facebook. Science 348: 1130-1132.

Barberá P, Jost JT, Nagler J, et al. (2015) Tweeting from left to right: Is online political communication more than an echo chamber. Psychological Science 26: 1531-1542.

Benkler Y (2006) The Wealth of Networks: How Social Production Transforms Markets and Freedom. New Haven: Yale University Press.

Bennett WL and Iyengar S (2008) A new era of minimal effects? The changing foundations of political communication. Journal of Communication 58: 707-731. 
Berelson B (1949) What 'missing the newspaper' means. In: Lazarsfeld PF and Stanton FN (eds), Communication Research 1948-1949, New York: Harper, pp. 111-129.

Boczkowski P, Mitchelstein E and Matassi M (2017) Incidental news: How young people consume news on social media. In: Proceedings of the 50th Hawaii International Conference on System Sciences, Hawaii, USA, pp. 1785-1792.

Bode L (2016a) Political news in the news feed: Leaning politics from social media. Mass Communication and Society 19(1): 24-48.

Bode L (2016b) Pruning the news feed: Unfriending and unfollowing political content on social media. Research and Politics 3(3): 1-8.

Bowyer BT, Kahne JE and Middaugh E (2015) Youth comprehension of political messages in YouTube videos. New Media \& Society 0(0): 1-20.

Broersma M and Graham T (2012) Social media as beat: Tweets as a news source during the 2010 British and Dutch elections. Journalism Practice 6: 403-419.

Chadwick A (2013) The Hybrid Media System: Politics and Power. New York, NY: Oxford University Press.

Downs A (1957) An Economic Theory of Democracy. New York: Harper.

Esser F, de Vreese CH, Strömbäck J, et al. (2012) Political information opportunities in Europe: A longitudinal and comparative study of thirteen television systems. International Journal of Press/Politics 17: 247-274.

Flaxman S, Goel S and Rao JM (2016) Filter bubbles, echo chambers, and online news consumption. Public Opinion Quarterly 80: 298-320. 
Fletcher R, Radcliffe D, Levy DAL, et al. (2015) Reuters Institute Digital News Report 2015: Supplementary Report. Oxford: Reuters Institute for the Study of Journalism, University of Oxford.

Gil de Zúñiga H, Jung N and Valenzuela S (2012) Social media use for news and individuals’ social capital, civic engagement and political participation. Journal of ComputerMediated Communication 17: 319-336.

Gil de Zúñiga H, Weeks B and Ardèvol-Abreu A (2017) Effects of the news-finds-me perception in communication: Social media use implications for news seeking and learning about politics. Journal of Computer-Mediated Communication 22(3): 105123.

Graber DA (1984) Processing the News: How People Tame the Information Tide. New York: Longman.

Heatherly KA, Lu Y and Lee JK (2016) Filtering out the other side? Cross-cutting and likeminded discussions on social networking sites. New Media \& Society 0: 1-19.

Kim C and Lee JK (2016) Social media type matters: Investigating the relationship between motivation and online social network heterogeneity. Journal of Broadcasting \& Electronic Media 60(4): 676-693.

Kim Y, Chen H-T and Gil de Zúñiga H (2013) Stumbling upon news on the internet: Effects of incidental news exposure and relative entertainment use on political engagement. Computers in Human Behavior 29: 2607-2614.

Lee JK and Kim E (2017) Incidental exposure to news: Predictors in the social media setting and effects on information gain online. Computers in Human Behavior 0(0): 1-8. 
Messing S and Westwood SJ (2014) Selective exposure in the age of social media: Endorsements trump partisan source affiliation when selecting news online. Communication Research 41: 1042-1063.

Neuman WR, Just MR and Crigler AN (1992) Common Knowledge: News and the Construction of Political Meaning. Chicago: University of Chicago Press.

Newman N, Levy DAL and Nielsen RK (2015) Reuters Institute Digital News Report 2015: Tracking the Future of News. Oxford: Reuters Institute for the Study of Journalism, University of Oxford.

Nielsen RK and Ganter SA (2017) Dealing with digital intermediaries: A case study of the relations between publishers and platforms. New Media \& Society 0(0): 1-18.

Norris P (2000) A Virtuous Circle: Political Communications in Postindustrial Societies. Cambridge: Cambridge University Press.

Pariser E (2011) Filter Bubbles: What the Internet is Hiding from You. London: Penguin.

Pew (2012a) Social Networking Sites and Politics. Washington D.C.: Pew Research Centre.

Pew (2012b) YouTube \& News: A New Kind of Visual Journalism. Washington D.C.: Pew Research Centre.

Pew (2016) News Use Across Social Media Platforms 2016. Washington D.C.: Pew Research Centre.

Prior M (2005) News vs. entertainment: How increasing media choice widens gaps in political knowledge and turnout. American Journal of Political Science 49: 577-592. 
Prior M (2009) The immensely inflated news audience: Assessing bias in self-reported news exposure. Public Opinion Quarterly 73: 130-143.

Rosania P (2015) While you were away... Twitter. Available from: https://blog.twitter.com/2015/while-you-were-away-0.

Stuart EA (2010) Matching methods for causal inference: A review and a look forward. Statistical Science 25(1): 1-21.

Tewksbury D, Weaver AJ and Maddex BD (2001) Accidentally informed: Incidental news exposure on the world wide web. Journalism \& Mass Communication Quarterly 78: 533-554.

Valeriani A and Vaccari C (2016) Accidental exposure to politics on social media as online participation equalizer in Germany, Italy, and the United Kingdom. New Media \& Society 18: 1857-1874.

Zuckerberg M (2015) We just passed an important milestone. Facebook. Available from: https://www.facebook.com/zuck/posts/10102329188394581.

\section{Notes}

${ }^{1}$ Excluding those who responded with Don't know from the analysis resulted in only minimal changes to the regression models, and did not affect the overall interpretation.

${ }^{2}$ An alternative approach would have been to place those who used each network for any purpose, but not for news, into the non-users category. This would have been a less conservative approach, given that people who said they had not 'used' each network for news might still have 'seen’ news there, potentially artificially inflating differences between nonusers and the incidentally exposed. However, this less conservative approach was also tested 
during post-analysis using the same techniques, and produced very similar results overall, suggesting that it makes little difference overall.

${ }^{3}$ An overdispersion test for each of the models revealed that the data was slightly overdispersed (a score of approximately 1.7 in each case). However, using negative binomial models did not result in a better fit. 
Table 1

Mean number of online news sources used in the last week

Non-users (SD) Incidentally exposed (SD) News users (SD)

\begin{tabular}{cccc}
\hline UK & $1.05(1.35)$ & $1.83(1.83)$ & $2.85(2.77)$ \\
USA & $1.68(2.13)$ & $2.61(2.67)$ & $3.85(3.61)$ \\
Italy & $1.78(1.98)$ & $2.64(2.43)$ & $3.60(3.35)$ \\
Australia & $1.60(1.59)$ & $2.16(1.94)$ & $3.01(2.22)$ \\
\hline All countries & $1.43(1.77)$ & $2.30(2.27)$ & $3.38(3.12)$ \\
\hline
\end{tabular}


Table 2

Poisson regression models where the dependent variable is number of online news sources used in the last week

\begin{tabular}{|c|c|c|c|c|c|c|c|c|}
\hline & \multicolumn{2}{|c|}{ Model 1} & \multicolumn{2}{|c|}{ Model 2} & \multicolumn{2}{|c|}{ Model 3} & \multicolumn{2}{|c|}{ Model 4} \\
\hline & $\mathrm{b}$ & SE & $\mathrm{b}$ & $\mathrm{SE}$ & $\mathrm{b}$ & SE & $\mathrm{b}$ & $\mathrm{SE}$ \\
\hline Incidentally exposed (IE) & $.26 * * *$ & .03 & $.66 * * *$ & .13 & $.88 * * *$ & .16 & $1.02 * * *$ & .17 \\
\hline Age & $-.20 * * *$ & .06 & $-.19 * * *$ & .06 & .19 & .19 & .20 & .20 \\
\hline Gender (Female) & $-.11 * * *$ & .02 & $-.11 * * *$ & .02 & $-.11 * * *$ & .02 & $-.11 * * *$ & .02 \\
\hline Education & $.49 * * *$ & .04 & $.49 * * *$ & .04 & $.47 * * *$ & .04 & $.49 * * *$ & .04 \\
\hline Trust in news & $.12 *$ & .05 & $.12 *$ & .05 & $.12 * *$ & .05 & $.12 *$ & .05 \\
\hline Interest in news & $1.06 * * *$ & .05 & $1.51 * * *$ & .14 & $1.47 * * *$ & .14 & $1.49 * * *$ & .14 \\
\hline Internet frequency & $.96 * * *$ & .07 & $.95 * * *$ & .07 & $.95 * * *$ & .07 & $.95 * * *$ & .07 \\
\hline Search for news & $.37 * * *$ & .02 & $.37 * * *$ & .02 & $.37 * * *$ & .02 & $.37 * * *$ & .02 \\
\hline News aggregator & $.39 * * *$ & .03 & $.39 * * *$ & .03 & $.39 * * *$ & .03 & $.39 * * *$ & .03 \\
\hline USA & $.34 * * *$ & .03 & $.34 * * *$ & .03 & $.34 * * *$ & .03 & $.44 * * *$ & .07 \\
\hline
\end{tabular}




\begin{tabular}{|c|c|c|c|c|c|c|c|c|}
\hline Italy & $.34 * * *$ & .03 & $.34 * * *$ & .03 & $.34 * * *$ & .03 & $.55 * * *$ & .09 \\
\hline Australia & $.14 * * *$ & .03 & $.14^{* * *}$ & .03 & $.14 * * *$ & .03 & $.33 * * *$ & .08 \\
\hline IE* Interest in news & & & $-.50 * * *$ & .15 & $-.46 * *$ & .15 & $-.48 * *$ & .15 \\
\hline IE*Age & & & & & $-.42 *$ & .20 & $-.43 *$ & .20 \\
\hline IE*USA & & & & & & & -.12 & .08 \\
\hline IE*Italy & & & & & & & $-.23 *$ & .09 \\
\hline IE*Australia & & & & & & & $-.22 *$ & .09 \\
\hline Constant & $-1.63 * * *$ & .09 & $-1.99 * * *$ & .14 & $-2.19 * * *$ & .17 & -2.31 & .18 \\
\hline Likelihood ratio $\mathrm{x}^{2}$ & \multicolumn{2}{|c|}{2502.22} & \multicolumn{2}{|c|}{2513.77} & \multicolumn{2}{|c|}{2518.06} & \multicolumn{2}{|c|}{2527.10} \\
\hline McFadden's Pseudo R ${ }^{2}$ & \multicolumn{2}{|c|}{.21} & \multicolumn{2}{|c|}{.21} & \multicolumn{2}{|c|}{.21} & \multicolumn{2}{|c|}{.21} \\
\hline $\mathrm{N}$ & \multicolumn{2}{|c|}{5765} & \multicolumn{2}{|c|}{5765} & \multicolumn{2}{|c|}{5765} & \multicolumn{2}{|c|}{5765} \\
\hline
\end{tabular}

$* \mathrm{p}<.05, * * \mathrm{p}<.01, * * * \mathrm{p}<.001$. 


\section{Appendix A}

Table 3

Poisson regression models for the matched Facebook dataset

\begin{tabular}{|c|c|c|c|c|c|c|}
\hline & \multicolumn{2}{|c|}{ Model 1} & \multicolumn{2}{|c|}{ Model 2} & \multicolumn{2}{|c|}{ Model 3} \\
\hline & $\mathrm{b}$ & $\mathrm{SE}$ & b & $\mathrm{SE}$ & $\mathrm{b}$ & SE \\
\hline Incidentally exposed (IE) & $.10 * * *$ & .02 & .01 & .02 & .07 & .04 \\
\hline IE on YouTube & & & $.24 * * *$ & .02 & $.23 * * *$ & .02 \\
\hline YouTube news user & & & $.39 * * *$ & .04 & $.39 * * *$ & .04 \\
\hline IE on Twitter & & & $.23 * * *$ & .02 & $.23 * * *$ & .02 \\
\hline Twitter news user & & & $.47 * * *$ & .03 & $.47 * * *$ & .03 \\
\hline Age & $-.44 * * *$ & .05 & $-.18 * * *$ & .05 & $-.17 * *$ & .05 \\
\hline Gender (Female) & $-.11 * * *$ & .02 & $-.06 * * *$ & .02 & $-.07 * * *$ & .02 \\
\hline Education & $.51 * * *$ & .04 & $.47 * * *$ & .04 & $.47 * * *$ & .04 \\
\hline
\end{tabular}




\begin{tabular}{|c|c|c|c|c|c|c|}
\hline Trust in news & $.10 *$ & .04 & $.10 *$ & .04 & $.10 *$ & .04 \\
\hline Interest in news & $1.08 * * *$ & .04 & $1.02 * * *$ & .04 & $1.02 * * *$ & .04 \\
\hline Internet frequency & $.89 * * *$ & .07 & $.69 * * *$ & .07 & $.69 * * *$ & .07 \\
\hline Search for news & $.41 * * *$ & .02 & $.36 * * *$ & .02 & $.36 * * *$ & .02 \\
\hline News aggregator & $.40 * * *$ & .03 & $.34 * * *$ & .03 & $.34 * * *$ & .03 \\
\hline USA & $.36 * * *$ & .02 & $.36 * * *$ & .02 & $.44 * * *$ & .05 \\
\hline Italy & $.34 * * *$ & .03 & $.34 * * *$ & .03 & $.43 * * *$ & .05 \\
\hline Australia & $.12 * * *$ & .03 & $.16^{* * *}$ & .03 & $.17 * *$ & .05 \\
\hline IE*USA & & & & & -.10 & .05 \\
\hline IE*Italy & & & & & $-.12 *$ & .06 \\
\hline IE*Australia & & & & & .00 & .06 \\
\hline Constant & $-1.29 * * *$ & .08 & $-1.36 * * *$ & .08 & $-1.41 * * *$ & .09 \\
\hline Likelihood ratio $\mathrm{x}^{2}$ & \multicolumn{2}{|c|}{2951.26} & \multicolumn{2}{|c|}{3483.60} & \multicolumn{2}{|c|}{3491.38} \\
\hline McFadden's Pseudo R ${ }^{2}$ & \multicolumn{2}{|c|}{.22} & \multicolumn{2}{|c|}{.26} & \multicolumn{2}{|c|}{.26} \\
\hline $\mathrm{N}$ & \multicolumn{2}{|c|}{6218} & \multicolumn{2}{|c|}{6218} & \multicolumn{2}{|c|}{6218} \\
\hline
\end{tabular}

${ }^{*} \mathrm{p}<.05, * * \mathrm{p}<.01, * * * \mathrm{p}<.001$. 
Table 4

Poisson regression models for the matched YouTube dataset

\begin{tabular}{|c|c|c|c|c|c|c|}
\hline & \multicolumn{2}{|c|}{ Model 1} & \multicolumn{2}{|c|}{ Model 2} & \multicolumn{2}{|c|}{ Model 3} \\
\hline & $\mathrm{b}$ & $\mathrm{SE}$ & $\mathrm{b}$ & $\mathrm{SE}$ & b & SE \\
\hline Incidentally exposed (IE) & $.28 * * *$ & .02 & $.23 * * *$ & .02 & $.31 * * *$ & .04 \\
\hline IE on Facebook & & & .00 & .02 & .00 & .02 \\
\hline Facebook news user & & & $.11 * * *$ & .03 & $.11 * * *$ & .03 \\
\hline IE on Twitter & & & $.19 * * *$ & .02 & $.19 * * *$ & .02 \\
\hline Twitter news user & & & $.43 * * *$ & .03 & $.43 * * *$ & .03 \\
\hline Age & $-.41 * * *$ & .05 & $-.21 * * *$ & .05 & $-.21 * * *$ & .05 \\
\hline Gender (Female) & $-.07 * * *$ & .02 & $-.06 * * *$ & .02 & $-.06 * * *$ & .02 \\
\hline Education & $.44 * * *$ & .04 & $.42 * * *$ & .04 & $.43 * * *$ & .04 \\
\hline Trust in news & $.11 * *$ & .04 & $.08 *$ & .04 & $.08 *$ & .04 \\
\hline Interest in news & $1.06 * * *$ & .04 & $.98 * * *$ & .04 & $.98 * * *$ & .04 \\
\hline
\end{tabular}




\begin{tabular}{|c|c|c|c|c|c|c|}
\hline Internet frequency & $.78 * * *$ & .06 & $.66 * * *$ & .06 & $.66 * * *$ & .06 \\
\hline Search for news & $.34 * * *$ & .02 & $.32 * * *$ & .02 & $.32 * * *$ & .02 \\
\hline News aggregator & $.39 * * *$ & .03 & $.35 * * *$ & .03 & $.35 * * *$ & .03 \\
\hline USA & $.33 * * *$ & .02 & $.36 * * *$ & .02 & $.41 * * *$ & .05 \\
\hline Italy & $.32 * * *$ & .02 & $.34 * * *$ & .02 & $.44 * * *$ & .05 \\
\hline Australia & $.10 * * *$ & .03 & $.16^{* * *}$ & .03 & $.23 * * *$ & .05 \\
\hline IE*USA & & & & & -.07 & .05 \\
\hline IE*Italy & & & & & $-.13 *$ & .05 \\
\hline IE*Italy & & & & & -.09 & .06 \\
\hline Constant & $-1.21 * * *$ & .08 & $-1.20 * * *$ & .08 & $-1.26 * * *$ & .08 \\
\hline Likelihood ratio $\mathrm{x}^{2}$ & \multicolumn{2}{|c|}{2991.69} & \multicolumn{2}{|c|}{3330.94} & \multicolumn{2}{|c|}{3337.19} \\
\hline McFadden's Pseudo R ${ }^{2}$ & \multicolumn{2}{|c|}{.21} & \multicolumn{2}{|c|}{.24} & \multicolumn{2}{|c|}{.24} \\
\hline $\mathrm{N}$ & \multicolumn{2}{|c|}{6298} & \multicolumn{2}{|c|}{6298} & \multicolumn{2}{|c|}{6298} \\
\hline
\end{tabular}

$* \mathrm{p}<.05, * * \mathrm{p}<.01, * * * \mathrm{p}<.001$. 
Table 5

Poisson regression models for the matched Twitter dataset

\begin{tabular}{|c|c|c|c|c|c|c|}
\hline & \multicolumn{2}{|c|}{ Model 1} & \multicolumn{2}{|c|}{ Model 2} & \multicolumn{2}{|c|}{ Model 3} \\
\hline & $\mathrm{b}$ & SE & $\mathrm{b}$ & SE & b & SE \\
\hline Incidentally exposed (IE) & $.32 * * *$ & .03 & $.27 * * *$ & .03 & $.33 * * *$ & .06 \\
\hline IE on Facebook & & & .02 & .04 & .02 & .04 \\
\hline Facebook news user & & & $.09 *$ & .04 & $.09 *$ & .04 \\
\hline IE on YouTube & & & $.23 * * *$ & .03 & $.23 * * *$ & .04 \\
\hline YouTube news user & & & $.32 * * *$ & .06 & $.32 * * *$ & .06 \\
\hline Age & $-.18 *$ & .08 & -.10 & .08 & -.10 & .08 \\
\hline Gender (Female) & $-.07 *$ & .03 & $-.06 *$ & .03 & $-.06 *$ & .03 \\
\hline Education & $.36 * * *$ & .06 & $.35 * * *$ & .06 & $.35 * * *$ & .06 \\
\hline Trust in news & .01 & .06 & .03 & .06 & .03 & .06 \\
\hline Interest in news & $.94 * * *$ & .07 & $.94 * * *$ & .07 & $.93 * * *$ & .07 \\
\hline
\end{tabular}




\begin{tabular}{|c|c|c|c|c|c|c|}
\hline Internet frequency & $.72 * * *$ & .11 & $.64 * * *$ & .11 & $.64 * * *$ & .11 \\
\hline Search for news & $.29 * * *$ & .03 & $.26 * * *$ & .03 & $.26 * * *$ & .03 \\
\hline News aggregator & $.36 * * *$ & .04 & $.34 * * *$ & .04 & $.34 * * *$ & .04 \\
\hline USA & $.42 * * *$ & .04 & $.39 * * *$ & .04 & $.43^{* * *}$ & .06 \\
\hline Italy & $.42 * * *$ & .04 & $.37 * * *$ & .04 & $.43 * * *$ & .06 \\
\hline Australia & $.25 * * *$ & .04 & $.23 * * *$ & .04 & $.24 * * *$ & .07 \\
\hline IE*USA & & & & & -.10 & .07 \\
\hline IE*Italy & & & & & -.09 & .08 \\
\hline IE*Australia & & & & & .00 & .08 \\
\hline Constant & $-1.08 * * *$ & .13 & $-1.19 * * *$ & .14 & $-1.22 * * *$ & .14 \\
\hline Likelihood ratio $\mathrm{x}^{2}$ & \multicolumn{2}{|c|}{1071.53} & \multicolumn{2}{|c|}{1141.13} & \multicolumn{2}{|c|}{1144.23} \\
\hline McFadden's Pseudo R ${ }^{2}$ & \multicolumn{2}{|c|}{.21} & \multicolumn{2}{|c|}{.23} & \multicolumn{2}{|c|}{.28} \\
\hline $\mathrm{N}$ & \multicolumn{2}{|c|}{2211} & \multicolumn{2}{|c|}{2211} & \multicolumn{2}{|c|}{2211} \\
\hline
\end{tabular}

